\title{
What is practical in glaucoma management?
}

\begin{abstract}
This article addresses some important issues in the detection and management of glaucoma using examples from the developing world, particularly drawing on experiences and research in sub-Saharan Africa.
\end{abstract}

Eye (2005) 19, 1125-1132. doi:10.1038/sj.eye.6701972

Keywords: glaucoma; Africa; trabeculectomy; screening; blindness

\section{Introduction}

There are an estimated 67 million people in the world with primary glaucoma, of whom it has been suggested that between 5.2 and 6.7 million are blind. ${ }^{1,2}$ Glaucoma thus constitutes the second most common cause of global blindness after cataract. More than $95 \%$ of those blind from glaucoma are from countries in the developing world, mostly in Asia and subSaharan Africa, because of a combination of their relative demographic weight, high prevalence of glaucoma, and poor access to health care. ${ }^{1}$

Half of those with primary glaucoma have angle-closure. These cases are concentrated in East Asia and ethnic groups derived from this part of the world such as the Inuit. The disease is more often a chronic asymptomatic disorder in these populations than the acute form more commonly seen in Caucasians. The other half are open-angle glaucoma (OAG) cases and this is the most common form of the disease in Caucasian and African-derived populations.

Glaucoma is classified by the World Health Organisation among the $80 \%$ of blindness deemed avoidable. However, glaucoma does not appear among the conditions identified as immediate priorities within the framework of VISION 2020. The choice of priority conditions (ie cataract, trachoma, onchocerciasis, childhood blindness, and refractive errors and low vision) is based on the burden of blindness they
A Rotchford

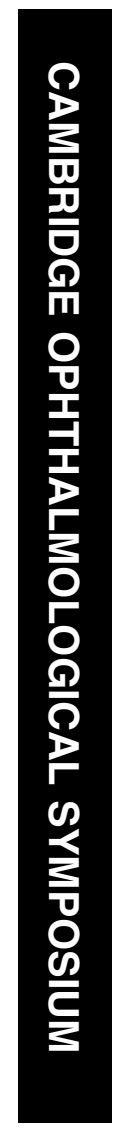

represent, and the feasibility and affordability of interventions to prevent and treat them. Glaucoma certainly achieves the first of these and if the VISION 2020 initiative is successful in its aim to eliminate blindness caused by the five priority conditions, then glaucoma is likely to be left as the leading cause of global blindness. The problem is that a number of features of glaucoma make fulfilling the other criteria difficult to achieve. Loss of vision caused by glaucoma is irreversible, the disease is usually asymptomatic in its early stages, difficult to detect, and therapeutic options are less attractive than, for example, cataract surgery.

As a result, glaucoma attracts little publicity or funding in the developing world and only a very limited proportion of cases are diagnosed or treated.

This article addresses some of the issues in the detection and management of OAG, using examples from the developing world,

particularly drawing on experiences in Africa.

\section{Case detection}

Among people with glaucoma in the developed world, reports from prevalence surveys suggest that only about half are likely to have been diagnosed (Table 1). In developing countries, the number is probably nearer to 1 in 10 or even less in the remotest and poorest-served parts of the world (Table 2).

Why is such a small proportion of glaucoma diagnosed? There is evidence that detection rates vary according to the type of glaucoma (Figure 1). Loss of vision appears to be more severe in angle-closure glaucoma (ACG) than POAG in populations where both are prevalent $(P=0.002)$, which may underlie the somewhat higher detection rate in ACG $(P=0.005)$ that is reported.

However, low detection rates cannot be entirely attributed to a lack of awareness of symptoms because, in the developing world, a significant proportion of undiagnosed cases are already severely affected. The majority of even
Queen's Medical Centre, Nottingham, Notts, UK

Correspondence: A Rotchford, Queen's Medical Centre, Derby Road, Nottingham, Notts NG7 2UH, UK Tel: + 44115 9249924; Fax: + 441159709749

E-mail: rotchford@ supanet.com

Received: 29 April 2005 Accepted: 2 May 2005 
Table 1 Percentage of cases of glaucoma previously detected in recent glaucoma prevalence surveys in Established Market Economies

\begin{tabular}{|c|c|c|}
\hline & $\%$ & Type glaucoma \\
\hline Roscommon $^{3}$ & 51 & POAG \\
\hline Melbourne ${ }^{4}$ & 50 & POAG \\
\hline Baltimore $^{5}$ & 50 & POAG \\
\hline Melbourne $^{4}$ & 50 & POAG and XFG \\
\hline Blue $\mathrm{Mts}^{6}$ & 49 & POAG \\
\hline Rotterdam ${ }^{7}$ & 47 & POAG \\
\hline Norway $^{8}$ & 27 & POAG \\
\hline Italy $^{9}$ & 22 & All \\
\hline Beaver Dam ${ }^{10}$ & 10 & POAG \\
\hline Italy $^{11}$ & 8 & POAG \\
\hline
\end{tabular}

Primary open-angle glaucoma (POAG); exfoliative glaucoma (XFG).

Table 2 Percentage of cases of glaucoma previously detected in recent glaucoma prevalence surveys in developing world countries

\begin{tabular}{lrl}
\hline & $\%$ & Type glaucoma \\
\hline Bangkok $^{12}$ & 25 & POAG \\
Pondoland $^{13}$ & 14 & All \\
Temba, S. Africa $^{14}$ & 13 & POAG \\
Singapore $^{15}$ & 9 & POAG \\
India $^{16}$ & 7 & POAG \\
Zululand $^{17}$ & 4 & POAG \\
Tanzania $^{18}$ & 2 & POAG \\
Mongolia $^{19}$ & 0 & POAG \\
\hline
\end{tabular}

Primary open-angle glaucoma (POAG).

Table 3 Percentage of glaucoma cases blind in one and/or both eyes in glaucoma prevalence surveys

\begin{tabular}{lcl}
\hline & One/both & Type glaucoma \\
\hline Mongolia $^{19}$ & 50.0 & All \\
Zululand $^{17}$ & 44.6 & All \\
Singapore $^{15}$ & 42.1 & All \\
Bangkok $^{12 a}$ & 22.2 & All \\
India $^{16}$ & 18.5 & POAG \\
Tanzania $^{18}$ & 18.0 & POAG \\
Rotterdam $^{\text {aa }}$ & 11.7 & POAG \\
Sweden $^{20 a}$ & 'rare' & All \\
\hline
\end{tabular}

Include severe restriction of visual field to within central $10^{\circ}$ except in those marked,

${ }^{a}$ which are based on visual acuity criteria only.

advanced disease goes undetected (Table 3). For example, in a glaucoma prevalence survey in rural South Africa, it was found that $45 \%$

$(21 / 47)$ of those with glaucoma were blind in at least one eye as a result. ${ }^{17}$ Of these, only five were previously known cases. So more than three-quarters of those blind

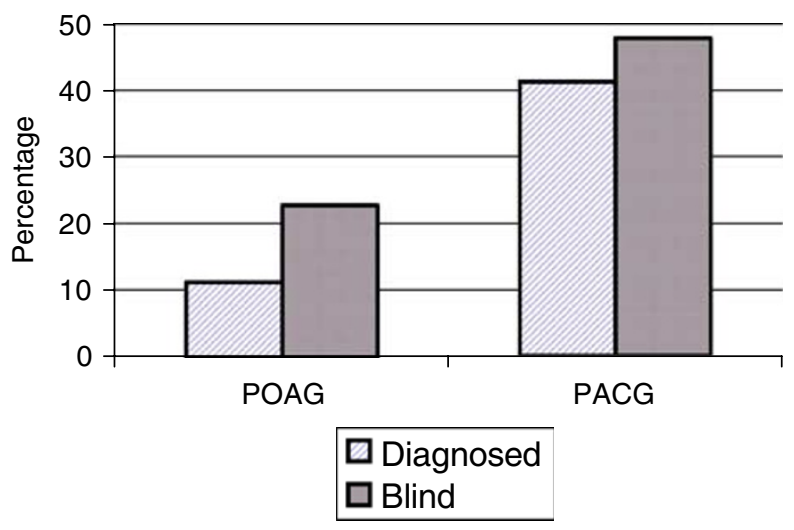

Figure 1 Blindness in one or both eyes and detection rates for different glaucoma types in prevalence surveys in Asia (Mongolia, Singapore, Thailand, and India).

from glaucoma in at least one eye were undiagnosed at the time of the survey.

Late presentation with glaucoma appears to be the norm in much of the world. For example, in Ghana, more than $50 \%$ of patients were blind at first presentation to hospital. ${ }^{21}$ Patients living more than 50 miles from the hospital were four times more likely to present blind than patients living within 50 miles of the hospital. This would suggest that what is required is a simple means of detecting glaucoma in the community.

For many disorders, formal screening is an important part of reducing the burden of disease in the population. ${ }^{22}$ However, before any population-based screening programme can be established, a number of criteria must be met, which include:

1. The condition must be a significant public health issue.

2. There should be a recognisable early stage during which those with disease can be identified before symptoms develop.

3. There should be a screening test which is simple, acceptable, safe, and precise.

4. An effective and acceptable treatment should exist, which results in quantifiable improvements in clinical outcome.

In most populations in the developing world, glaucoma meets the first criterion of constituting an important public health problem, but identifying a test that reliably diagnoses glaucoma in its early stages remains problematic.

There are essentially three tests used in the diagnosis of OAG, which have been evaluated for their potential as screening tools. These are tonometry, optic disc/nerve fibre layer examination, and visual field testing. Unfortunately, none of these has a high level of 
sensitivity and specificity such that most cases are detected without an excessive number of false positives.

\section{Tonometry}

IOP is distributed in the population as a continuous variable and there is no cutoff that discriminates between normal eyes and those with glaucoma. In some populations, the degree of overlap is quite considerable (Figure 2). This is reflected in the relatively high proportion of those with glaucoma who present with IOP within the normal range.

In many population-based glaucoma surveys, this proportion is 50\% or higher (Tables 4 and 5). To make matters worse, it is now clear that mean IOP in normal eyes varies between populations. The mean population IOP in Barbados, for example, was found to be nearly $50 \%$ higher than that in Mongolia. ${ }^{28,19}$ Any screening test based on tonometry therefore has to take into account the distribution of IOP in that particular population. The risk of glaucoma increases gradually with IOP as a result of which precision of IOP as a screening test for glaucoma is poor at whatever level of IOP is selected. For example, in South Africa, at a cutoff of $>21 \mathrm{mmHg}$, tonometry had a

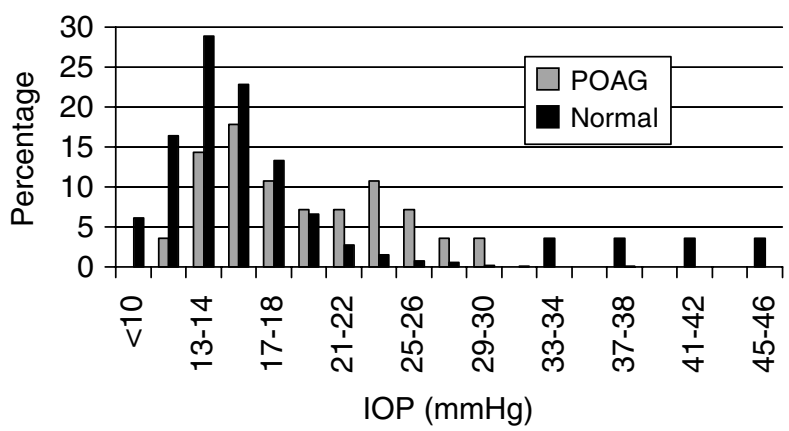

Figure 2 The overlapping distributions of IOP in POAG and normal Zulu eyes.

Table 4 Proportion of glaucoma cases with intraocular pressure $<21 \mathrm{mmHg}$ in developed countries

\begin{tabular}{lll}
\hline & $\%$ & Type glaucoma \\
\hline Blue Mts $^{6}$ & 74 & POAG \\
Roscommon $^{3}$ & 62 & POAG \\
Sweden $^{20}$ & 61 & POAG \\
Baltimore $^{23}$ & 55 & POAG \\
Melbourne $^{4}$ & 39 & POAG \\
Rotterdam $^{7}$ & 39 & POAG \\
Wales $^{24}$ & 35 & POAG \\
Beaver Dam & POAG \\
Italy $^{9}$ & 32 & All \\
Italy $^{11}$ & 29 & POAG \\
\hline
\end{tabular}

sensitivity of only $37 \%$ and specificity of $91 \%$ for the detection of POAG (Figure 3), figures which are very similar to those reported from the Baltimore Eye Study. ${ }^{29}$

\section{Optic disc examination}

Ophthalmologists rely heavily on the appearance of the optic disc to help in the diagnosis of glaucoma. However, disc changes in early glaucoma can be subtle and agreement on disc examination by ophthalmoscopy has been reported as being relatively low. It appears to be higher with more sophisticated methods such as stereoscopic disc photography, ${ }^{30}$ but these are by and large impractical in the developing world situation.

The cup: disc ratio (CDR) is a widely used numerical assessment of the state of the neuroretinal rim. Unlike IOP, it does appear to be well conserved between different ethnic groups (Table 6), but it is also distributed as a continuous variable with no sharp cutoff point.

Furthermore, disc cup size is determined in part by disc diameter so that a large disc will have a large cup and

Table 5 Proportion of glaucoma cases with intraocular pressure $<21 \mathrm{mmHg}$ in developing countries

\begin{tabular}{lll}
\hline & $\%$ & Type glaucoma \\
\hline Tanzania $^{18}$ & 75 & POAG \\
Bangkok $^{12}$ & 69 & POAG \\
India $^{16}$ & 59 & POAG \\
Zululand $^{17}$ & 57 & POAG \\
Barbados $^{25}$ & 50 & POAG \\
Temba, S. Africa $^{14}$ & 36 & POAG \\
St Lucia & POA & Pfrica \\
Mamre, S. Afria & 36 & POAG \\
\hline
\end{tabular}

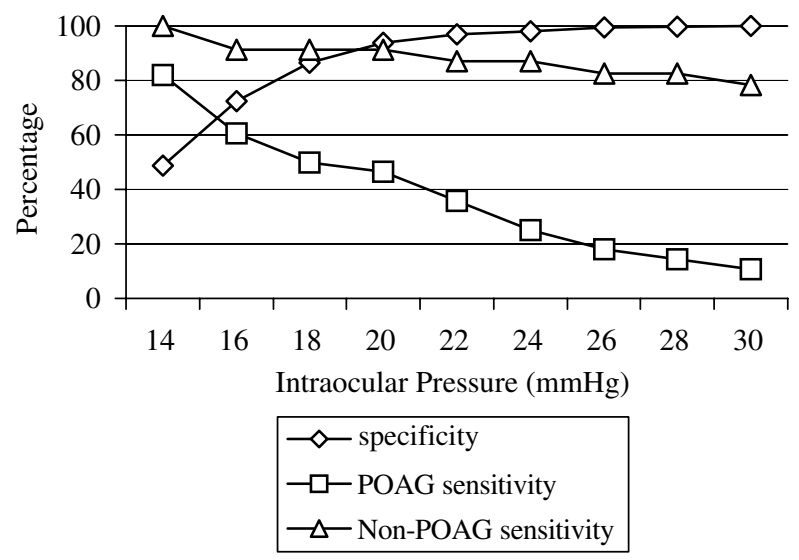

Figure 3 Sensitivity and specificity for different cutoff values of IOP in detecting glaucoma in Zulus. 
Table 6 Vertical cup: disc ratio (CDR) and CDR asymmetry in population-based studies ${ }^{31,3 a}$

\begin{tabular}{lcclccc}
\hline & \multicolumn{2}{c}{ Vertical $C D R$} & & \multicolumn{2}{c}{ CDR asymmetry } \\
\cline { 2 - 3 } \cline { 6 - 6 } & $\begin{array}{l}\text { 97.5th } \\
\text { centile }\end{array}$ & $\begin{array}{c}\text { 99.5th } \\
\text { centile }\end{array}$ & & $\begin{array}{c}\text { 97.5th } \\
\text { centile }\end{array}$ & $\begin{array}{c}\text { 99.5th } \\
\text { centile }\end{array}$ \\
\hline Bangladesh & 0.70 & 0.85 & & 0.15 & 0.3 \\
Mongolia & 0.70 & 0.70 & & 0.2 & 0.3 \\
Thailand & 0.72 & 0.86 & & 0.21 & 0.29 \\
Singapore & 0.71 & 0.82 & & 0.21 & 0.32 \\
Tanzania & 0.7 & 0.8 & & 0.2 & 0.3 \\
Zululand & 0.7 & 0.9 & & 0.2 & 0.3 \\
\hline
\end{tabular}

${ }^{a}$ Visual field testing was carried out in all subjects except those in Bangladesh with IOP $<18 \mathrm{mmHg}$ and $\mathrm{CDR}<0.35$.

vice versa. ${ }^{32}$ Overall, CDR does not appear to perform any better than IOP as an isolated screening test and the use of various combinations of disc parameters and IOP does not help significantly. ${ }^{29}$

\section{Perimetry}

Automated perimetry has been shown to have relatively high sensitivity and specificity when used as a screening test. ${ }^{33,34}$ However, visual field testing is time consuming and requires sophisticated equipment and trained, wellmotivated operators. It is also not always easy to reproduce in practice the level of validity quoted from studies. In an American sample, sensitivity of $97 \%$ and specificity of $100 \%$ were achieved using the Henson suprathreshold screening programme. In a rural South African population, by contrast, sensitivity and specificity fell to 79 and $90 \%$, respectively.

People also find field testing a difficult task to perform. In rural South Africa, more than $90 \%$ of sighted over 40-year-olds were able to complete the screening test. But this proportion fell dramatically among the elderly (71\% in those over 70 years of age) and those with visual impairment (44\% in those with acuity in the better eye $<6 / 24)$. Since this is the section of the population most at risk of glaucoma, this represents a significant drawback.

Whether other types of visual field testing such as frequency doubling perimetry will present a practical solution remains to be seen.

Whether other types of visual field testing such as frequency doubling perimetry will present a practical solution remains to be seen. ${ }^{35}$

\section{Summary of screening and case detection}

Since there is not yet a good screening test for OAG, the emphasis should be on detecting cases of advanced glaucoma who are at substantial risk of progressing to blindness and who require urgent treatment.

To help achieve this realistic goal, patients who present to ophthalmologists and are over the age of 40 years (and possibly younger in some African populations ${ }^{21}$ ) should undergo tonometry and optic-disc assessment as part of their examination. Failure, at present, to perform these simple procedures routinely means that cases of wellestablished glaucoma are missed. ${ }^{16}$

The importance of considering a diagnosis of glaucoma even in those without raised IOP needs to be stressed in training programmes for ophthalmologists.

General population screening for POAG cannot be recommended until a test which is reliable and simple to apply, and which more accurately discriminates between affected and unaffected people, is available. In the meantime, the emphasis should be on detecting cases who already have advanced glaucoma and are at substantial risk of progressing to blindness and require urgent treatment. Making a diagnosis of glaucoma in those with advanced disease is a realistic goal in the developing world.

In situations where eye patients are seen by nonophthalmologists, ideally, tonometry and optic-disc assessment need to be taught and used routinely. Nonophthalmologists can accurately detect higher degrees of disc cupping using direct ophthalmoscopy even in undilated patients. ${ }^{36}$ Clear criteria for referral to an ophthalmologist should be given. In practical terms these criteria must be simple and specific enough not to overburden the service with false positives. For example

- unexplained visual loss;

- $\mathrm{IOP}>25 \mathrm{mmHg}$;

- CDR of 0.8 or more.

Using these criteria, a significantly higher proportion of glaucoma would be detected than is currently the case in most developing countries, with a few inappropriate referrals. For example, in rural South Africa, 95\% of eyes with a CDR 0.8 or more had a threshold visual field defect consistent with glaucoma. This cutoff would have detected $64 \%(18 / 28)$ of eyes with moderate/severe visual field defects. ${ }^{17}$

\section{Treatment of glaucoma}

The only proven effective treatment for glaucoma to date is the reduction of IOP to a level that reduces the rate of loss of visual field. In developed world countries, it is current practice to initiate treatment either with laser trabeculoplasty or topical medication, or a combination of the two. Surgery in the form of a drainage procedure is usually reserved for those for whom these initial treatments are inadequate. 
In the developing world, trabeculoplasty is generally unavailable as an option and poor compliance is an even greater barrier to successful medical management of glaucoma than it is in the developed world. This is mainly because of logistical problems such as the long distance many have to travel to access eye care facilities to collect their treatment, and the relatively high cost of medications. There is also the problem of convincing patients of the need for continuation of treatment for life in spite of the lack of improvement in their vision and even possible side effects. Without this understanding, many patients become discouraged and stop using their treatment. In Ghana, it was found that among patients treated medically who returned for follow-up at 6 months, only $17 \%$ had an intraocular pressure less than $22 \mathrm{mmHg}$. While of the patients treated surgically, $84 \%$ of those seen at 6 months had an IOP below $22 \mathrm{mmHg}^{21}$

For these reasons, medical treatment of glaucoma in poorly educated patients in the developing world is usually inappropriate. In these circumstances, when there may only be 'one shot' at the patient, primary surgical intervention is usually the treatment of choice. ${ }^{37}$

\section{Trabeculectomy in blacks}

There is a strong clinical impression that filtration surgery is less successful in patients from pigmented racial groups than in whites. Results from the Advanced Glaucoma Intervention Study (AGIS), in which a large number of African-American and white patients with medically uncontrolled POAG were randomised to one of two sequences of surgical intervention, support this impression..$^{38}$ In the arm undergoing trabeculectomy as the first intervention, most glaucoma-related outcomes including the level of IOP, required number of medications and progression of field loss were worse in black than in white subjects. Despite the use of antimetabolite in only two out of 379 eyes for which trabeculectomy was the first intervention, the proportion requiring a second surgical intervention after 9 years of follow-up was relatively low in both racial groups but was significantly higher for black (18\%) than white subjects $(13 \%)$.

\section{Trabeculectomy in the developing world}

These results cannot necessarily be extrapolated to the developing world, however. Later presentation with more advanced disease, variable quality of operating facilities and technique, low rates of follow-up, and poor compliance with postoperative medications would suggest that the results of surgery would be worse in poorer countries.
Interpretation of the results of filtration procedures in underdeveloped countries has been dogged by short follow-up periods and loss to follow-up rates up to $80 \%$ or more. ${ }^{39}$ Prior to the era of antimetabolites, reported success rates in African series (mostly defined as IOP $<21 \mathrm{mmHg}$ without additional medication) vary considerably between 28 and $95 \% .{ }^{39}$

In a retrospective series of 100 patients with POAG undergoing nonaugmented trabeculectomy in Nigeria with mean follow-up of 34 months, success (defined as IOP $<22 \mathrm{mmHg}$ and a $>30 \%$ reduction in preoperative IOP with or without medication) was achieved in $85 \%$ after 1 year, falling to $71 \%$ after 5 years. ${ }^{40}$

Over the last few years, the use of the anti-metabolites 5-fluourouracil (5-FU) and mitomycin C (MMC) to modify the wound-healing response following filtration surgery has increased success rates for trabeculectomy in the developed world ${ }^{41}$ and they are now in common use in eyes considered to be at high risk of failure.

Several groups have reported on the use of peroperative antimetabolite in developing countries. ${ }^{42-48}$

In an unmasked randomised trial in a population with advanced glaucoma (93\% POAG) in Ghana, a significant beneficial effect for intraoperative subconjunctival 5-FU at a dose of $50 \mathrm{mg} / \mathrm{ml}$ for 5 min was reported.$^{45}$ Failure (defined as IOP $>21 \mathrm{mmHg}$ ) occurred in $13 \%$ for 5 -FU compared to $45 \%$ for controls, although minimum follow-up was only 3 months $(P=0.01)$.

The same group also compared intraoperative 5-FU and MMC $(0.5 \mathrm{mg} / \mathrm{ml}$ for $3.5 \mathrm{~min}) .^{43}$ After a mean followup of 10 months, an IOP $\leq 21 \mathrm{mmHg}$ was found in $93 \%$ in the MMC group compared with $73 \%$ in the 5 -FU group $(P=0.01)$. Overall $57 \%$ achieved IOP $\leq 15 \mathrm{mmHg}$ with no significant difference between the two groups.

In a double-blind randomised placebo controlled trial of 5-FU in Kenyan patients with POAG, IOP was similar in the two arms after 6 months. ${ }^{46}$ Among the $44 \%$ who were followed for 2 years, $89 \%$ of 5 -FU subjects and $71 \%$ of controls had an IOP $<22 \mathrm{mmHg}$, but this difference was not statistically significant.

In black South Africans with refractory glaucoma, a higher proportion of eyes treated intraoperatively with MMC had postoperative IOP below $21 \mathrm{mmHg}$ than matched controls (83 vs 37\%, $P<0.001$ ). ${ }^{42}$

A number of conclusions with implications for the management of glaucoma in developing countries can be drawn from the results of these studies. Firstly, achieving a reasonable length of follow-up for the majority of patients in this type of context is very difficult even with the extra effort to minimise the default rate when the patient is part of a study. Secondly, although failure occurs most frequently in the first 6 months after surgery, it continues thereafter at a significant rate. ${ }^{40,46}$ Interpreting the effectiveness of trabeculectomy and the 
merits of adjunctive antimetabolites over short time periods and in a limited proportion of the sample is therefore hazardous. Certainly success rates would be expected to fall if patients had been followed up for longer.

Thirdly, although the success rates are lower than those reported in developed countries, the difference may be attributed at least in part to differences in surgical technique and postoperative interventions such as suture removal/lysis, manipulation of the bleb, and tailored steroid dosage. Nevertheless trabeculectomy, especially with 5-FU or MMC, is effective at reducing IOP in the majority, at least in the short term.

Finally, surgical complication rates are not insignificant despite the relative experience of most of the surgeons in the studies. Sight-threatening intraoperative complications were uncommon, but less serious complications such as transient wound leak, hypotony, and hyphaema were more frequent and are important since they have been linked to trabeculectomy failure ${ }^{49}$ and cataract formation. ${ }^{50}$ The Loss of two or more Snellen lines following trabeculectomy was reported in 6.5-30\% of cases, with cataract being the most frequent cause. The proportion losing this degree of visual acuity is important, especially given that in many cases it is the better-seeing eye that is undergoing surgery.

In the developing world, patients may not present for surgery a second time when they develop cataract, especially if they perceive that the trabeculectomy has contributed to their loss of vision. This is likely to act as a further barrier to acceptance of surgery in poorer communities.

There are additional hazards associated with the use of both 5-FU and MMC. There is an increased risk of wound leaks, and late bleb leaks from thin-walled, cystic blebs that predispose to hypotony and endophthalmitis. In a trial in South Africa, cystic blebs occurred in $63 \%$ of cases treated with MMC, with leaking in $16.7 \% .^{42}$ This experience has led to a reduction in the use of antimetabolites in some units.

Longer studies are required to determine the effectiveness of trabeculectomy including subsequent cataract surgery and the long-term effects of antimetabolites on bleb morphology. While there is no doubt that the use of antimetabolites improves the success rate of trabeculectomy in high-risk patients, it remains unclear exactly who benefits and which antimetabolite is best. There is some evidence that lower IOP can be achieved following with MMC than with $5 F U$, but the difference is not as great as the difference between 5FU and no antimetabolite. In the developing world, the higher cost and refrigerated storage requirements of $\mathrm{MMC}$ are further considerations. The techniques involved in their use are also still evolving. ${ }^{41}$
In particular, modifications have been suggested that seem to help produce diffuse noncystic blebs that drain posteriorly. These modifications include the use of large scleral flaps under a fornix-based conjuctival flap and a large surface area of antimetabolite treatment. The results of a randomised controlled trial of beta radiation applied to the bleb via a probe during surgery in black South Africans is anticipated and may provide a further option.

\section{Compliance}

We are only going to make an impact on the number of people going blind from glaucoma if we can provide a treatment that is not only effective but also acceptable to those at risk.

However, the uptake of surgery among patients with eye disease in developing countries is generally less than satisfactory. ${ }^{51-53}$ Problems with recruitment for cataract surgery appear to be universal in developing countries, although the major barriers to acceptance vary. ${ }^{52,53}$ Not surprisingly, the cost and the distance to be travelled have been identified as important barriers.

However, even establishing a free local surgical facility does not guarantee good uptake. In rural South Africa, we identified several other fundamental attitudinal barriers to the uptake of cataract surgery, including the fear of surgery (both the process and the outcome) and a fatalistic attitude to the inevitability and irreversibility of blindness in old age. There was a lower level of disability and perceived need than had been assumed for people with such poor visual acuity, and many said that they were able to cope without any intervention. ${ }^{51}$

Although these patients had cataract rather than glaucoma, it is reasonable to assume that many of the same attitudes towards the treatment and prevention of blindness would be the same. If anything, patients offered glaucoma surgery would be even less likely to accept since their level of visual handicap would not be as significant and the results of treatment less certain.

Among the few people to look at this important issue are Kirwan and co-workers (JF Kirwan, personal communication). They identified 90 new cases of primary open-angle or exfoliation glaucoma presenting to a hospital in Pietermaritzburg, South Africa. They described the features of these 90 new cases and compared them with 40 cases identified in a populationbased glaucoma survey performed in black South Africans in a neighbouring province. ${ }^{14}$ More than $80 \%$ had at least a moderate degree of visual loss in one eye and half were blind in one eye. Patients attending the clinic were significantly younger and had higher IOP than patients identified in a glaucoma survey in a similar population. ${ }^{14}$ 
Out of the 90 new cases, 77 with acuity better than perception of hand movement in the affected eye were offered trabeculectomy. Of these only 33 (43\%) accepted the offer. Those that accepted were no different in terms of age or severity of visual loss. They had higher IOP, which it was suggested may reflect greater encouragement by the examining clinician to undergo surgery.

\section{Conclusions}

- Glaucoma is a major cause of blindness and is likely to become an even more prominent cause of blindness as other treatable causes are dealt with.

- Glaucoma does not meet the criteria for general population screening mainly because of the lack of a simple and precise screening tool. Nevertheless, every opportunity should be taken to detect cases by considering the diagnosis and performing an appropriate examination. Disc assessment by ophthalmoscopy and, to a lesser extent, tonometry require little specialist skill or sophisticated equipment. They have a reasonably high degree of specificity in detecting advanced glaucoma. These patients are the most likely to go blind and are more likely to present and comply with treatment.

- It must be assumed that the patient may only present once. Despite the added risks, appropriate treatment is generally trabeculectomy supplemented, where appropriate, in patients at high risk of failure with an antimetabolite. The long-term outcome and complication rates in the developing world have not yet been fully assessed.

- It is likely that compliance with surgery will be higher if there is good experience of successful surgical outcome for cataract in the area. This is often not the case with significant numbers of patients remaining blind after surgery. The importance of quality in all types of ophthalmic surgery cannot be stressed enough. This issue is now receiving far more attention where, before, volume of surgery has been stressed and, hopefully, the widespread introduction of ECCE and IOL implantation will lead to higher levels of patient satisfaction and trust in their surgeon.

\section{References}

1 Thylefors B, Negrel AD, Pararajasegaram R, Dadzie KY. Global data on blindness. Bull World Health Organ 1995; 73: 115-121.

2 Quigley HA. Number of people with glaucoma worldwide. Br J Ophthalmol 1996; 80: 389-393.
3 Coffey M, Reidy A, Wormald R, Xian WX, Wright L, Courtney P. Prevalence of glaucoma in the west of Ireland. Br J Ophthalmol 1993; 77: 17-21.

4 Wensor MD, McCarty CA, Stanislavsky YL, Livingston PM, Taylor HR. The prevalence of glaucoma in the Melbourne Visual Impairment Project. Ophthalmology 1998; 105: 733-739.

5 Tielsch JM, Sommer A, Katz J, Royall RM, Quigley HA, Javitt J. Racial variations in the prevalence of primary openangle glaucoma. The Baltimore Eye Survey. JAMA 1991; 266(3): 369-374.

6 Mitchell P, Smith W, Chey T, Healey PR. Open-angle glaucoma and diabetes: the Blue Mountains eye study, Australia. Ophthalmology 1997; 104: 712-718.

7 Dielemans I, Vingerling JR, Wolfs RC, Hofman A, Grobbee DE, de Jong PT. The prevalence of primary openangle glaucoma in a population-based study in The Netherlands. The Rotterdam Study. Ophthalmology 1994; 101: 1851-1855.

8 Ringvold A, Blika S, Elsas T, Guldahl J, Brevik T, Hesstvedt $\mathrm{P}$ et al. The middle-Norway eye-screening study. II. Prevalence of simple and capsular glaucoma. Acta Ophthalmol (Copenh) 1991; 69: 273-280.

9 Bonomi L, Marchini G, Marraffa M, Bernardi P, De Franco I, Perfetti $S$ et al. Prevalence of glaucoma and intraocular pressure distribution in a defined population. The Egna-Neumarkt Study. Ophthalmology 1998; 105: 209-215.

10 Klein BE, Klein R, Sponsel WE, Franke T, Cantor LB, Martone J et al. Prevalence of glaucoma. The Beaver Dam Eye Study. Ophthalmology 1992; 99: 1499-1504.

11 Cedrone C, Culasso F, Cesareo M, Zapelloni A, Cedrone P, Cerulli L. Prevalence of glaucoma in Ponza, Italy: a comparison with other studies. Ophthalmic Epidemiol 1997; 4: 59-72.

12 Bourne R, Sukodom P, Foster P, Tantisevi V, Jitapunkul S, Lee PS et al. Prevalence of glaucoma in Thailand: a population-based survey in Rom Klao District, Bangkok. $\mathrm{Br}$ J Ophthalmol 2003; 87: 1-6.

13 Bartholomew R. Glaucoma in a South African Black Population. S Afr Arch Ophthalmol 1976; 3: 135-150.

14 Rotchford AP, Kirwan JF, Muller MA, Johnson GJ, Roux P. Temba glaucoma study: a population-based cross-sectional survey in urban South Africa. Ophthalmology 2003; 110: 376-382.

15 Foster P, Oen F, Machin D, Ng T, Devereux JG, Johnson GJ et al. The prevalence of glaucoma in chinese residents of Singapore. Arch Ophthalmol 2000; 118: 1105-1111.

16 Dandona L, Dandona R, Srinivas M, Mandal P, John RK, McCarty CA et al. Open-angle glaucoma in an urban population in southern India: the Andhra Pradesh eye disease study. Ophthalmology 2000; 107: 1702-1709.

17 Rotchford AP, Johnson GJ. Glaucoma in Zulus: a population-based cross-sectional survey in a rural district in South Africa. Arch Ophthalmol 2002; 120: 471-478.

18 Buhrmann R, Quigley H, Barron Y, West SK, Oliva MS, Mbaga BB. Prevalence of glaucoma in a rural East African population. Invest Ophthalmol Vis Sci 2000; 41: 40-48.

19 Foster PJ, Baasanhu J, Alsbirk PH, Munkhbayar D, Uranchimeg D, Johnson GJ. Glaucoma in Mongolia. A population-based survey in Hovsgol province, northern Mongolia. Arch Ophthalmol 1996; 114: 1235-1241.

20 Bengtsson B. The prevalence of glaucoma. $\mathrm{Br}$ J Ophthalmol 1981; 65: 46-49. 
21 Verrey JD, Foster A, Wormald R, Akuamoa C. Chronic glaucoma in northern Ghana-a retrospective study of 397 patients. Eye 1990; 4: 115-120.

22 Wilson J, Jungner Y. Screening for Disease. WHO: Geneva, 1968.

23 Sommer A, Tielsch JM, Katz J, Quigley HA, Gottsch JD, Javitt J et al. Relationship between intraocular pressure and primary open angle glaucoma among white and black Americans. The Baltimore Eye Survey. Arch Ophthalmol 1991; 109: 1090-1095.

24 Hollows F, Graham P. The Ferndale Glaucoma Survey. In: Hunt L (ed). Glaucoma, Epidemiology, Early Diagnosis and Some Aspects of Treatment. Proceedings of a Symposium Held at The Royal College of surgeons of England, June 1965. Livingstone Ltd: Edinburgh, London, 1966, pp 24-44.

25 Leske MC, Connell AM, Schachat AP, Hyman L. The Barbados Eye Study. Prevalence of open angle glaucoma. Arch Ophthalmol 1994; 112: 821-829.

26 Mason RP, Kosoko O, Wilson MR, Martone JF, Cowan Jr CL, Gear JC et al. National survey of the prevalence and risk factors of glaucoma in St. Lucia, West Indies. Part I. Prevalence findings. Ophthalmology 1989; 96: 1363-1368.

27 Salmon JF, Mermoud A, Ivey A, Swanevelder SA, Hoffman $\mathrm{M}$. The prevalence of primary angle closure glaucoma and open angle glaucoma in Mamre, western Cape, South Africa. Arch Ophthalmol 1993; 111: 1263-1269.

28 Leske MC, Connell AM, Wu SY, Hyman L, Schachat AP. Distribution of intraocular pressure. The Barbados Eye Study. Arch Ophthalmol 1997; 115: 1051-1057.

29 Tielsch JM, Katz J, Singh K, Quigley HA, Gottsch JD, Javitt J et al. A population-based evaluation of glaucoma screening: the Baltimore Eye Survey. Am J Epidemiol 1991; 134: 1102-1110.

30 Tielsch JM, Katz J, Quigley HA, Miller NR, Sommer A. Intraobserver and interobserver agreement in measurement of optic disc characteristics. Ophthalmology 1988; 95: 350-356.

31 Foster P, Buhrmann R, Quigley H, Johnson G. The definition and classification of glaucoma in prevalence surveys. $\mathrm{Br} \mathrm{J}$ Ophthalmol 2002; 86: 238-242.

32 Jonas JB, Fernandez MC, Naumann GO. Correlation of the optic disc size to glaucoma susceptibility. Ophthalmology 1991; 98: 675-680.

33 Katz J, Sommer A, Gaasterland DE, Anderson DR. Comparison of analytic algorithms for detecting glaucomatous visual field loss. Arch Ophthalmol 1991; 109(12): 1684-1689.

34 Sponsel W, Ritch R, Stamper R, Higginbotham E, Anderson $\mathrm{D}$, Wilson $\mathrm{M}$ et al. Prevent blindness America visual field screening study. Am J Ophthalmol 1995; 120: 699-708.

35 Cello KE, Nelson-Quigg JM, Johnson CA. Frequency doubling technology perimetry for detection of glaucomatous visual field loss. Am J Ophthalmol 2000; 129: 314-322.

36 Foster A, Wormald R, van de Heide A, Templeton K, Minassian D. Evaluation of ophthalmoscopy by nonophthalmologists in diagnosing chronic glaucoma in West Africa. Eye 1989; 3: 647-650.
37 Schwab L, Steinkuller PG. Surgical treatment of open angle glaucoma is preferable to medical management in Africa. Soc Sci Med 1983; 17: 1723-1727.

38 The Advanced Glaucoma Intervention Study (AGIS): 9. Comparison of glaucoma outcomes in black and white patients within treatment groups. Am J Ophthalmol 2001; 132: 311-320.

39 Broadway D, Murdoch I. Glaucoma in blacks. In: El Sayyad F (ed). The Refractory Glaucomas, Chapter 2 Igaku-Shoin Medical Publishers: New York, 1995, pp 31-54.

40 Anand N, Mielke C, Dawda VK. Trabulectomy outcomes in advanced glaucoma in Nigeria. Eye 2001; 15: 274-278.

41 Khaw PT. Advances in glaucoma surgery: evolution of antimetabolite adjunctive therapy. J Glaucoma 2001; 10: S81-S84.

42 Mermoud A, Salmon JF, Murray AD. Trabeculectomy with mitomycin $\mathrm{C}$ for refractory glaucoma in blacks. $A m \mathrm{~J}$ Ophthalmol 1993; 116: 72-78.

43 Singh K, Egbert PR, Byrd S, Budenz DL, Williams AS, Decker JH et al. Trabeculectomy with intraoperative 5-fluorouracil vs mitomycin C. Am J Ophthalmol 1997; 123: 48-53.

44 Singh K, Byrd S, Egbert PR, Budenz D. Risk of hypotony after primary trabeculectomy with antifibrotic agents in a black west African population. J Glaucoma 1998; 7: 82-85.

45 Egbert PR, Williams AS, Singh K, Dadzie P, Egbert TB. A prospective trial of intraoperative fluorouracil during trabeculectomy in a black population. Am J Ophthalmol 1993; 116: 612-616.

46 Yorston D, Khaw PT. A randomised trial of the effect of intraoperative 5-FU on the outcome of trabeculectomy in east Africa. Br J Ophthalmol 2001; 85: 1028-1030.

47 Quigley HA, Buhrmann RR, West SK, Isseme I, Scudder M, Oliva MS. Long term results of glaucoma surgery among participants in an east African population survey. $\mathrm{Br} \mathrm{J}$ Ophthalmol 2000; 84: 860-864.

48 Mwanza JC, Kabasele PM. Trabeculectomy with and without mitomycin-C in a black African population. Eur J Ophthalmol 2001; 11: 261-263.

49 The Advanced Glaucoma Intervention Study (AGIS 11). Risk factors for failure of trabeculectomy and argon laser trabeculoplasty. Am J Ophthalmol 2002; 134: 481-498.

50 The Advanced Glaucoma Intervention Study: 8. Risk of cataract formation after trabeculectomy. Arch Ophthalmol 2001; 119: 1771-1779.

51 Rotchford AP, Rotchford KM, Mthethwa LP, Johnson GJ. Reasons for poor cataract surgery uptake - a qualitative study in rural South Africa. Trop Med Int Health 2002; 7: 288-292.

52 Courtright P, Kanjaloti S, Lewallen S. Barriers to acceptance of cataract surgery among patients presenting to district hospitals in rural Malawi. Trop Geogr Med 1995; 47: 15-18.

53 Fletcher A, Donoghue M, Devavaram J, Thulasiraj R, Scott S, Abdalla $\mathrm{M}$ et al. Low uptake of eye services in rural India. Arch Ophthalmol 1999; 117: 1393-1399. 